\title{
Hypoxic Stress: A Key Regulator of the Antitumor Cytotoxic Response Linking Immune Resistance to Immune Suppression
}

\author{
Meriem Hasmim, Yosra Messai, Stéphane Terry, Stéphanie Buart, Muhammad Zaeem Noman and Salem Chouaib* \\ INSERM U 1186, Gustave Roussy Campus, 94805 Villejuif, France
}

*Corresponding author: Salem Chouaib, INSERM U 1186, Gustave Roussy Campus, Villejuif, France, Tel: +33142114852; Fax: +33142115288; E-mail: salem.chouaib@gustaveroussy.fr

Received date: March 24, 2015; Accepted date: March 26, 2015; Published date: April 02, 2015

Copyright: (C) 2015 Hasmim M, et al. This is an open-access article distributed under the terms of the Creative Commons Attribution License, which permits unrestricted use, distribution, and reproduction in any medium, provided the original author and source are credited.

\section{Editorial}

The tumor microenvironment is a complex network of tumor cells, immune cells, stromal cells and extracellular matrix accomplishing proliferation, migration, and dissemination of tumor cells. The reactivity of the immune system towards the growing tumor determines its capacity to reject the tumor, but this reactivity is increasingly appearing to be critically dependent on tumor microenvironmental factors. These factors include secreted molecules, type of infiltrating cells, and metabolic component such as hypoxia. Microenvironmental hypoxia is a prominent feature of solid tumors and is involved in fostering the neoplastic process and in modulation of immune reactivity. It results from inadequacies between the tumor microcirculation and the oxygen demands of the growing tumor mass, which leads to a lowering of oxygen partial pressure and a metabolic switch towards glycolysis [1]. Tumor hypoxia is a negative prognostic and predictive factor due to many effects on the selection of hypoxiasurviving clones [2], activation of the expression of genes involved in apoptosis inhibition [3], angiogenesis [4], invasiveness and metastasis [5], epithelial-to-mesenchymal transition [6], and loss of genomic stability [7]. Accumulating evidence indicates that tumor hypoxia is also involved in loss of immune reactivity either by decreasing tumor cell sensitivity to cytotoxic effectors or promoting immunosuppressive mechanisms [8].

The major effects of hypoxia are mediated through the stabilization of Hypoxia-inducible factors (HIFs) composed of a basic helix-loophelix/PAS protein (HIF- $\alpha$ ) and the aryl hydrocarbon nuclear translocator (ARNT or HIF- $\beta$ ). Under normoxia, HIF- $\alpha$ subunit is degraded following hydroxylation at proline residues by prolylhydroxylases (PHD), which allows the binding of the E3 ubiquitin ligase pVHL for proteasome-targeted degradation [9-11]. Under normoxia, HIF- $\alpha$ is also hydroxylated at asparagine residues by the asparaginyl-hydroxylase Factor Inhibiting HIF-1 (FIH) to prevent interactions with co-activators such as p300 and aberrant transcriptional activation $[10,11]$. In contrast, the $\beta$-subunit is not regulated by oxygen levels and is constitutively expressed in the nucleus. Hypoxia inhibits the hydroxylation of proline and asparagine residues, allowing HIF- $\alpha$ nuclear translocation and binding to HIF- $\beta$ for full transcriptional activation.

Recently, we provided evidence indicating that hypoxia induced resistance of tumor cells to the lytic action of cytotoxic effector cells via several HIF-1a -dependent mechanisms involving activation of Stat3 [12], induction of the embryonic factor Nanog [13], induction of miR-210 [14], autophagy activation [15] and Granzyme B degradation in autophagosmes [16]. It has also been reported that hypoxia was able to inhibit the activity of MICA, a ligand for activating receptor NKG2D, by increasing the shedding of MICA at the surface of target cells [17], or down-regulating MICA expression [18] leading to tumor escape from NK cells and CTLs.

More interestingly, the expression of $\mathrm{T}$ cell inhibitory checkpoints was found to be regulated by hypoxic stress. We have recently shown that hypoxia induced up-regulation of Program Death-Ligand 1 (PDL1), ligand of the inhibitory checkpoint PD-, on both tumor and Myeloid-Derived Suppressor Cells (MDSC) via direct binding of HIF-1 to PD-L1 promoter [19]. This establishes a direct link between immunosuppressive mechanisms and hypoxic signalling. Based on these findings, the combination of HIF-targeting molecules to immunotherapies and conventional anti-cancer therapies may provide a more efficacious and enduring response in cancer patients. HIF factors are also involved in the regulation of tumor cell response to cytotoxic effectors independently of oxygen levels in the context of inactivating VHL mutations. These mutations induce a constitutive stabilisation of HIFs, a process known as pseudo-hypoxia. In this regard, we reported that, in VHL-mutated clear cell renal cell carcinoma (RCC) cells, HIF-2 stabilization caused by mutated VHL induces upregulation of ITPR1 that mediates RCC resistance to NK via modulation of NK-induced autophagy [20].

Several other intra-cellular signalling pathways activated by hypoxia remains to be explored for their role in target response to CTL/NK effectors such as the glycolytic pathway or hypoxia-induced epithelialto-mesenchymal transition.

Hypoxia also contributes to the shaping of the tumor microenvironment by promoting immune tolerance through regulation of differentiation of regulatory $\mathrm{T}$ cells (Treg), macrophages, and myeloid-derived suppressor cells. In particular, under hypoxic stress and in the presence of TGF- $\beta$, CD4+ T cells upregulate Foxp3 through direct binding of HIF-1 to Foxp3 promoter region, inducing Treg formation [21]. Tumor hypoxia also attracts Treg inside the tumor bed by impacting the cytokinic profile inside the microenvironment. Facciabene et al. have recently reported that hypoxic stress increases the expression and secretion of CCL28 by tumor cells [22]. CCL28 act as a chemoattractant for Treg cells, whose immunosuppressive functions on CD8+ T cells are well documented. We have demonstrated that hypoxia-induced Nanog binds directly to TGF- $\beta$ promoter and upregulates TGF- $\beta 1$ expression and secretion, which is involved in majority Treg and macrophage infiltration into tumors [23]. Targeting Nanog reverses this trend with clear increase in CD8+ T cell and inhibition of Treg and macrophage infiltration. We cannot exclude that other hypoxia-induced factors (including cytokines and chemokines) may cooperate with TGF- $\beta 1$ to regulate Nanog-mediated immune suppression, but these findings connect stem cell-associated factors with inhibition of the immune response in the hypoxic tumor environment. 
Citation: Hasmim M, Messai Y, Terry S, Buart S, Noman MZ, et al. (2015) Hypoxic Stress: A Key Regulator of the Antitumor Cytotoxic Response Linking Immune Resistance to Immune Suppression. J Mol Genet Med 9: E104. doi:10.4172/1747-0862.1000E104

Page 2 of 2

Clearly, solid tumors develop a hostile hypoxic microenvironment that hamper cell-mediated immunity and dampen the immune response efficacy. Counteracting hypoxic signaling represents challenging strategy to avoid immune resistance and immunosuppressive signaling, and increase cancer immunotherapy efficacy.

\section{References}

1. Laconi E (2007) The evolving concept of tumor microenvironments Bioessays 29: 738-744

2. Graeber TG, Osmanian C, Jacks T, Housman DE, Koch CJ, et al. (1996) Hypoxia-mediated selection of cells with diminished apoptotic potential in solid tumours. Nature 379: 88-91.

3. Erler JT, Cawthorne CJ, Williams KJ, Koritzinsky M, Wouters BG, et al. (2004) Hypoxia-mediated down-regulation of Bid and Bax in tumors occurs via hypoxia-inducible factor 1-dependent and -independent mechanisms and contributes to drug resistance. Mol Cell Biol 24: 2875-2889.

4. Semenza GL (2000) Hypoxia, clonal selection, and the role of HIF-1 in tumor progression. Crit Rev Biochem Mol Biol 35: 71-103.

5. Pennacchietti S, Michieli P, Galluzzo M, Mazzone M, Giordano S, et al. (2003) Hypoxia promotes invasive growth by transcriptional activation of the met protooncogene. Cancer Cell 3: 347-361.

6. Hill RP, Marie-Egyptienne DT, Hedley DW (2009) Cancer stem cells, hypoxia and metastasis. Semin Radiat Oncol 19: 106-111.

7. Bristow RG, Hill RP (2008) Hypoxia and metabolism. Hypoxia, DNA repair and genetic instability. Nat Rev Cancer 8: 180-192.

8. Noman MZ, Messai Y, Carre T, Akalay I, Meron M, et al. (2011) Microenvironmental hypoxia orchestrating the cell stroma cross talk, tumor progression and antitumor response. Crit Rev Immunol 31: 357-377.

9. Salceda S, Caro J (1997) Hypoxia-inducible factor 1alpha (HIF-1alpha) protein is rapidly degraded by the ubiquitin-proteasome system under normoxic conditions. Its stabilization by hypoxia depends on redoxinduced changes. J Biol Chem 272: 22642-22647.

10. Wenger RH (2002) Cellular adaptation to hypoxia: O2-sensing protein hydroxylases, hypoxia-inducible transcription factors, and O2-regulated gene expression. FASEB J 16: 1151-1162.

11. Acker T, Fandrey J, Acker H (2006) The good, the bad and the ugly in oxygen-sensing: ROS, cytochromes and prolyl-hydroxylases. Cardiovasc Res 71: 195-207.
12. Noman MZ, Buart S, Van Pelt J, Richon C, Hasmim M, et al. (2009) The cooperative induction of hypoxia-inducible factor-1 alpha and STAT3 during hypoxia induced an impairment of tumor susceptibility to CTLmediated cell lysis. J Immunol 182: 3510-3521.

13. Hasmim M, Noman MZ, Lauriol J, Benlalam H, Mallavialle A, et al. (2011) Hypoxia-dependent inhibition of tumor cell susceptibility to CTLmediated lysis involves NANOG induction in target cells. J Immunol 187: 4031-4039.

14. Noman MZ, Buart S, Romero P, Ketari S, Janji B, et al. (2012) Hypoxiainducible miR-210 regulates the susceptibility of tumor cells to lysis by cytotoxic T cells. Cancer Res 72: 4629-4641.

15. Noman MZ, Janji B, Kaminska B, Van Moer K, Pierson S, et al. (2011) Blocking hypoxia-induced autophagy in tumors restores cytotoxic T-cell activity and promotes regression. Cancer Res 71: 5976-5986.

16. Baginska J, Viry E, Berchem G, Poli A, Noman MZ, et al. (2013) Granzyme B degradation by autophagy decreases tumor cell susceptibility to natural killer-mediated lysis under hypoxia. Proc Natl Acad Sci U S A 110: 17450-17455.

17. Siemens DR, Hu N, Sheikhi AK, Chung E, Frederiksen LJ, et al. (2008) Hypoxia increases tumor cell shedding of MHC class I chain-related molecule: role of nitric oxide. Cancer Res 68: 4746-4753.

18. Yamada N, Yamanegi K, Ohyama H, Hata M, Nakasho K, et al. (2012) Hypoxia downregulates the expression of cell surface MICA without increasing soluble MICA in osteosarcoma cells in a HIF-1 $\mathrm{I} \pm$-dependent manner. Int J Oncol 41: 2005-2012.

19. Noman MZ, Desantis G, Janji B, Hasmim M, Karray S, et al. (2014) PDL1 is a novel direct target of HIF-1a, and its blockade under hypoxia enhanced MDSC-mediated T cell activation. J Exp Med 211: 781-790.

20. Messai Y, Noman MZ, Hasmim M, Janji B, Tittarelli A, et al. (2014) ITPR1 protects renal cancer cells against natural killer cells by inducing autophagy. Cancer Res 74: 6820-6832.

21. Clambey ET, McNamee EN, Westrich JA, Glover LE, Campbell EL, et al. (2012) Hypoxia-inducible factor-1 alpha-dependent induction of FoxP3 drives regulatory $\mathrm{T}$-cell abundance and function during inflammatory hypoxia of the mucosa. Proc Natl Acad Sci U S A 109: E2784-2793.

22. Facciabene A, Peng X, Hagemann IS, Balint K, Barchetti A, et al. (2011) Tumour hypoxia promotes tolerance and angiogenesis via CCL28 and T(reg) cells. Nature 475: 226-230.

23. Hasmim M, Noman MZ, Messai Y, Bordereaux D, Gros G, et al. (2013) Cutting edge: Hypoxia-induced Nanog favors the intratumoral infiltration of regulatory $\mathrm{T}$ cells and macrophages via direct regulation of TGF- $\hat{I}^{2} 1$. J Immunol 191: 5802-5806. 